\title{
A rapid and simple quantitative method for specific detection of smaller coterminal RNA by PCR (DeSCo-PCR): application to the detection of viral subgenomic RNAs
}

\author{
PULKIT KANODIA, ${ }^{1,2}$ K. REDDISIVA PRASANTH, ${ }^{3}$ VICKY C. ROA-LINARES, ${ }^{3,4}$ SHELTON S. BRADRICK, ${ }^{3,7}$ \\ MARIANO A. GARCIA-BLANCO, ${ }^{3,5,6}$ and W. ALLEN MILLER ${ }^{1,2}$ \\ ${ }^{1}$ Interdepartmental Genetics and Genomics, lowa State University, Ames, lowa 50011, USA \\ ${ }^{2}$ Plant Pathology and Microbiology Department, lowa State University, Ames, lowa 50011, USA \\ ${ }^{3}$ Department of Biochemistry and Molecular Biology, University of Texas Medical Branch, Galveston, Texas 77555, USA \\ ${ }^{4}$ Molecular and Translational Medicine Group, Institute of Medical Research, Faculty of Medicine University of Antioquia, \\ Medellin 050010, Colombia \\ ${ }^{5}$ Programme of Emerging Infectious Diseases, Duke-NUS Medical School, Singapore 169857, Singapore \\ ${ }^{6}$ Institute of Human Infections and Immunity, University of Texas Medical Branch, Galveston, Texas 77555, USA
}

\begin{abstract}
RNAs that are $5^{\prime}$-truncated versions of a longer RNA but share the same $3^{\prime}$ terminus can be generated by alternative promoters in transcription of cellular mRNAs or by replicating RNA viruses. These truncated RNAs cannot be distinguished from the longer RNA by a simple two-primer RT-PCR because primers that anneal to the cDNA from the smaller RNA also anneal to-and amplify-the longer RNA-derived cDNA. Thus, laborious methods, such as northern blot hybridization, are used to distinguish shorter from longer RNAs. For rapid, low-cost, and specific detection of these truncated RNAs, we report detection of smaller coterminal RNA by PCR (DeSCo-PCR). DeSCo-PCR uses a nonextendable blocking primer (BP), which outcompetes a forward primer (FP) for annealing to longer RNA-derived cDNA, while FP outcompetes BP for annealing to shorter RNA-derived cDNA. In the presence of BP, FP, and the reverse primer, only cDNA from the shorter RNA is amplified in a single-tube reaction containing both RNAs. Many positive strand RNA viruses generate $5^{\prime}$-truncated forms of the genomic RNA (gRNA) called subgenomic RNAs (sgRNA), which play key roles in viral gene expression and pathogenicity. We demonstrate that DeSCo-PCR is easily optimized to selectively detect relative quantities of sgRNAs of red clover necrotic mosaic virus from plants and Zika virus from human cells, each infected with viral strains that generate different amounts of sgRNA. This technique should be readily adaptable to other sgRNA-producing viruses, and for quantitative detection of any truncated or alternatively spliced RNA.
\end{abstract}

Keywords: truncated RNA; flavivirus; Tombusviridae; Zika virus; long noncoding RNA

\section{INTRODUCTION}

Many positive sense RNA viruses generate $3^{\prime}$ coterminal subgenomic RNAs (sgRNAs) in infected cells. These include many pathogens such as human norovirus, chikungunya, Zika, and dengue viruses, and important plant pathogens such as barley yellow dwarf (BYDV) and maize chlorotic mottle viruses. Most viral sgRNAs, including those of the above viruses, are simply $5^{\prime}$-truncated versions of the viral genome, usually being less than half the length of the full-length genomic RNA (Miller and Koev 2000; Sztuba-

\footnotetext{
7Present address: MRIGlobal, Kansas City, MO 64110, USA Corresponding author: wamiller@iastate.edu

Article is online at http://www.rnajournal.org/cgi/doi/10.1261/rna. 074963.120. Freely available online through the RNA Open Access
} option.
Solińska et al. 2011). sgRNAs can serve as mRNAs for translation of open reading frames (ORFs) located downstream from the 5'-proximal ORF(s) that are translated from genomic RNA (Sztuba-Solińska et al. 2011). More recently, sgRNAs have been found that are derived from the $3^{\prime}$ untranslated region (UTR) of the viral genome, and thus function as noncoding sgRNAs (ncsgRNAs) (Iwakawa et al. 2008; Pijlman et al. 2008; Peltier et al. 2012).

For plant viruses in the Tombusviridae, Luteoviridae, Solemoviridae, Bromoviridae, Virgaviridae, Benyviridae families, and the order Tymovirales, and animal viruses in the Togaviridae (e.g., chikungunya virus), Caliciviridae

(C) 2020 Kanodia et al. This article, published in RNA, is available under a Creative Commons License (Attribution 4.0 International), as described at http://creativecommons.org/licenses/by/4.0/. 
(e.g., human norovirus), Astroviridae (human astrovirus) families, ORFs encoding the RNA-dependent RNA polymerase and associated replicase proteins, located in the $5^{\prime}$ half of the genome, are translated from the viral genomic RNA (gRNA). However, for translation of $5^{\prime}$ distal ORFs that encode proteins required at middle or late stages of infection, such as structural proteins, one or more sgRNAs are generated (Monroe et al. 1993; Koev and Miller 2000; Miller and Koev 2000; Sztuba-Solińska et al. 2011; Royall and Locker 2016; Contigiani and Diaz 2017). For example, the nonstructural polyprotein ORF (including the replicase) of members of Togaviridae is translated from gRNA, while the polyprotein ORF encoding structural proteins is translated from a sgRNA that is $3^{\prime}$ coterminal with the gRNA (Strauss and Strauss 1994).

Certain viruses in the Luteoviridae (Shen and Miller 2004; Shen et al. 2006; Miller et al. 2015), Tombusviridae (Scheets 2000; Iwakawa et al. 2008) and Benyviridae (Peltier et al. 2012; Flobinus et al. 2016 , 2018) families, and all viruses in the Flavivirus genus (Pijlman et al. 2008; Roby et al. 2014) generate ncsgRNAs from the 3' UTR that play an important role in regulating virus gene expression, virus movement and transmission, with major effects on pathogenicity and symptom development. However, their mechanisms of action are only just beginning to be understood. For example, (i) BYDV sgRNA2 regulates translation of gRNA and sgRNA1 (Shen et al. 2006; Miller et al. 2015), (ii) beet necrotic yellow vein virus sgRNA3 is required for long-distance movement in plants (Peltier et al. 2012), and (iii) subgenomic flavivirus RNAs (sfRNA) interfere with the innate immune systems of mammalian and insect hosts (Schnettler et al. 2012; Bidet and Garcia-Blanco 2014; Bidet et al. 2014; Roby et al. 2014; Manokaran et al. 2015; Donald et al. 2016; Miller et al. 2016; Finol and Ooi 2019).

In this study, we detected sgRNAs of red clover necrotic mosaic virus (RCNMV) and Zika virus (ZIKV). RCNMV (Family: Tombusviridae, Genus: Dianthovirus, Fig. 1A) is a bipartite plant virus with positive-sense single-stranded gRNA1 and gRNA2 (Gould et al. 1981; Hiruki 1987). During infection, a coding sgRNA generated from the $3^{\prime}$ end of gRNA1 serves as the mRNA for viral coat protein translation (Sit et al. 1998). RCNMV also generates a ncsgRNA, SR1f, as a stable degradation product formed by incomplete degradation of gRNA and coat protein sgRNA by a plant $5^{\prime}$ to $3^{\prime}$ exonuclease (lwakawa et al.
2008; Steckelberg et al. 2018). SR1f is not required for infection of the highly susceptible host plant, Nicotiana benthamiana, as an RCNMV mutant that is unable to generate SR1f accumulates substantial levels of the viral genomic RNAs and the coat protein sgRNA (Iwakawa et al. 2008). However, this mutant is unable to accumulate substantially in Arabidopsis thaliana.

ZIKV (Family: Flaviviridae; Genus: Flavivirus; Fig. 1B) usually causes an acute, mild febrile illness, but in the 2015 South and Central American epidemic was found to cause neurological disorders such as microcephaly in infants born to infected mothers and Guillain-Barre syndrome in adults (Beckham et al. 2016; Ferraris et al. 2019). One of the molecular determinants of pathogenicity of ZIKV and other flaviviruses is the sfRNA, which, like $\mathrm{SR} 1 \mathrm{f}$, is an incomplete degradation product of gRNA by a host $5^{\prime}$ to $3^{\prime}$ exonuclease (Pijlman et al. 2008; Silva et al. 2010). RCNMV SR1f and the sfRNAs of ZIKV and other flaviviruses are not required for viral replication but increase virus titer and disease severity (Iwakawa et al. 2008; Pijlman et al. 2008; Moon et al. 2012, 2015; Schnettler et al. 2012; Schuessler et al. 2012; Bidet et al. 2014; Roby et al. 2014; Akiyama et al. 2016; Göertz et al. 2016; Lee et al. 2019). For example, dengue virus disease severity appears to correlate positively with sfRNA level in infected cells. Screening viral mutants that vary in level of sgRNA accumulation is crucial to the understanding of the role of these sgRNAs in viral infection. 
In order to (i) decipher the role of ncsgRNA, (ii) identify cis- or trans-acting RNA elements in a sgRNA, (iii) understand the function of proteins encoded by sgRNAs, (iv) identify promoters required for sgRNA synthesis, (v) undertake field surveys for viral strains with particularly severe symptoms controlled by sgRNA levels, etc., rapid detection of sgRNA and measurement of expression is important. While gRNA can be measured by a simple two-primer based RT-PCR with PCR primers that can hybridize to any region across the gRNA, detection of sgRNAs as distinct from gRNA currently requires more cost- and time-intensive methods, usually northern blot hybridization (Kessler et al. 1990; Amiss and Presnell 2005). In addition, northern blot hybridization is less sensitive compared to RT-PCR and requires several micrograms of total RNA as input. Indirect ways of estimating sgRNA levels include quantitative RT-PCR (qRT-PCR) in which abundance of gRNA, as calculated by gRNA-specific qRT-PCR, is subtracted from total abundance of gRNA and sgRNA, as calculated by qRT-PCR using primers that anneal to their coterminal region (Bidet et al. 2014), or deep sequencing (e.g., Illumina) of total RNA in an infected cell and simply comparing the number of reads that map to the sgRNA region vs the upstream gRNA. However, this too is expensive, time-consuming and requires much bioinformatics analysis post-sequencing. Also, Illumina read counts can vary significantly across a viral genome in the absence of sgRNA (Xu et al. 2019).

To overcome the difficulties and costs associated with the above methods, an RT-PCR approach would be preferable. However, as mentioned above, a simple two-primer based RT-PCR cannot distinguish sgRNA-derived cDNA (sgRNA cDNA) from gRNA-derived cDNA (gRNA cDNA). For an RT-PCR reaction with coterminal RNAs, any primer-pair designed to amplify the sgRNA cDNA will also anneal to the gRNA cDNA, owing to their coterminal ends, resulting in amplification from both, making RT-PCR futile for specific detection of sgRNA. To prevent amplification from gRNA cDNA and enable selective amplification from sgRNA cDNA, we have developed a three-primer based RT-PCR approach, which we name DeSCo-PCR (detection of smaller coterminal RNA by PCR). This method is easy to optimize, relatively simple, quick and inexpensive for specific detection of sgRNAs.

\section{RESULTS}

\section{Overview of the DeSCo-PCR method}

DeSCo-PCR utilizes a nonextendable blocking primer (BP) with two amplification primers to prevent amplification of gRNA under conditions that permit amplification of the sgRNA (Fig. 2). Firstly, cDNA to be used as template for DeSCo-PCR is prepared from total RNA, using a virus sequence-specific reverse primer (Fig. 2A). DeSCo-PCR uses three primers (Fig. 2B): (i) a reverse primer (RP) that anneals to gRNA cDNA and sgRNA cDNA at their coterminal 5 ' end (complementary to the $3^{\prime}$-coterminal ends of the viral RNAs), (ii) a forward primer (FP), containing the sequence of the $5^{\prime}$ end of the sgRNA, that can anneal to both gRNA cDNA and sgRNA cDNA, and (iii) a long ( 50-nt) forward nonextendable BP containing a contiguous gRNA sequence upstream and downstream from the sgRNA $5^{\prime}$ end followed by a tract of nonviral bases at its $3^{\prime}$ end, which makes it nonextendable by the polymerase (explained in detail below). Under PCR conditions, BP out-competes FP for annealing to gRNA cDNA because it has more bases that can anneal to gRNA cDNA. However, BP is nonextendable and hence, amplification cannot occur from gRNA cDNA. For annealing to sgRNA cDNA, FP outcompetes BP because FP has more bases that can anneal to sgRNA cDNA, resulting in amplification of sgRNA cDNA. Thus, in the presence of all three primers, only sgRNA cDNA is amplified but not the gRNA cDNA (Fig. 2C).

\section{Blocking primer design for DeSCo-PCR}

Blocking primer $(\mathrm{BP})$ is a DeSCo-PCR specific primer that is 50-60-nt long and has three regions (Fig. 2B; dashed box): (i) competitive region (CR), the first 40-nt of the primer that can anneal only to gRNA sequence (just upstream of the $5^{\prime}$ end of sgRNA sequence) but not to sgRNA sequence; (ii) blocking region (BR), the $\sim 10$-nt middle region of the primer that can anneal to both gRNA and sgRNA sequences at the $5^{\prime}$ end of the sgRNA (entire sequence of BR is present in the FP); (iii) nonextendable region (NER), the 3 -terminal $\sim 6$-nt of the primer with any nontemplate bases that ensure that the $3^{\prime}$ end of the primer cannot anneal to either the gRNA or sgRNA sequence. Because the 3' end of the primer cannot anneal, the polymerase cannot extend and hence, amplify from the template. FP and CR-BR sequences of BP can anneal to gRNA sequence. The melting temperature $\left(T_{m}\right)$ of CR-BR should be significantly higher than FP so that BP will out-compete FP for annealing to gRNA sequence during PCR. FP and BR can anneal to sgRNA sequence. $T_{m}$ of FP should be higher than that of BR so that FP will out-compete BP for annealing to sgRNA sequence. The NER should not be included for any $T_{m}$ calculations. It is preferable to calculate $T_{m}$ according to buffer conditions of the PCR reaction. For example, if Promega GoTaq master mix is used, $T_{m}$ should be calculated using the " $T_{m}$ for Oligos" tool on its website (https://www.promega.com/resources/tools/biomath/) with the appropriate master mix specified.

\section{General guidelines for optimizing DeSCo-PCR}

For optimizing DeSCo-PCR conditions, either in vitro transcribed gRNA and sgRNA can be reverse transcribed and 


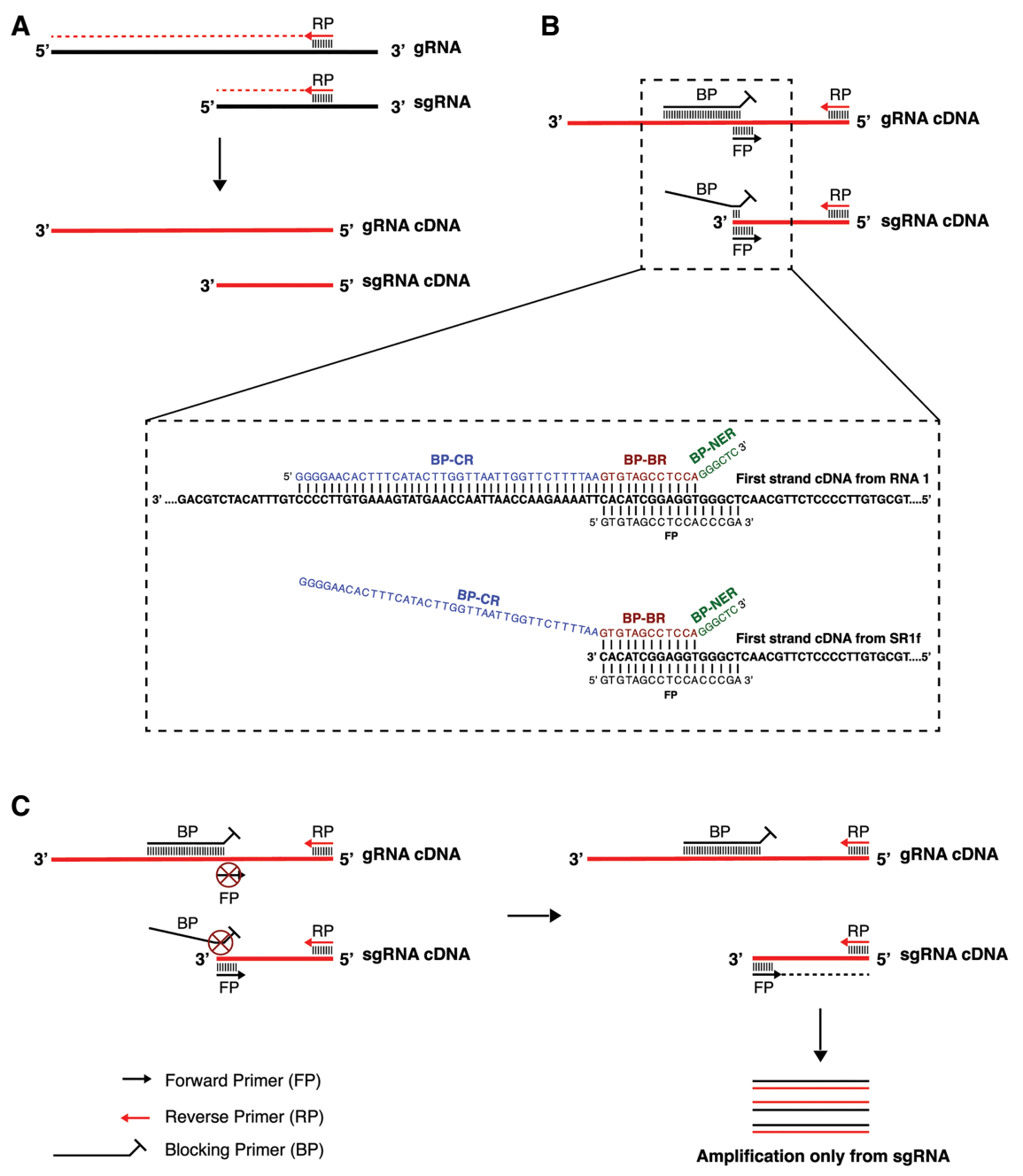

FIGURE 2. Schematic diagram of DeSCo-PCR. (A) First-strand cDNA synthesis (red line) using template-specific reverse primer (RP) annealed to viral positive-strand RNA (bold black line). (B) Primer schematics indicating annealing of BP mostly upstream but extending downstream from the $5^{\prime}$ end of sgRNA sequence and annealing of FP to a longer tract starting exactly at the $5^{\prime}$ end of sgRNA sequence. This allows BP to win the annealing competition for gRNA and FP to win the annealing competition for the $5^{\prime}$ end of sgRNA. The dashed box shows the sequences of BP and FP primers and the partial cDNA sequences of RCNMV RNA1 and SR1f to which the primers anneal. (C) Primer competition at annealing step and subsequent extension step of DeSCo-PCR. Vertical lines represent base-pairing between the primers and the cDNA template. Circled Xindicates primer that does not anneal in the presence of competing primer. (gRNA) genomic RNA, (sgRNA) subgenomic RNA, (FP) forward primer, (BP) blocking primer, (CR) competitive region (blue letters), (BR) blocking region (red letters), (NER) nonextendable region (green letters).

the resulting first-strand cDNA product can be used as template for PCR, or one can use DNA templates with (i) sequence of sgRNA and (ii) at least partial gRNA sequence that includes sgRNA sequence and 100 nt upstream of sgRNA. All DeSCo-PCR reactions should be conducted with low ramp-rate for the annealing step of PCR.

The main determinant of PCR parameters is the template concentration. Therefore, in vitro transcribed (IVT) viral RNA concentration or the dilution of CDNA that gives similar band intensity by RT-PCR to that from infected tissues should be determined to serve as a positive control. Next, a gradient PCR with $\sim 25$ cycles should be performed with FP plus RP to determine the maximum annealing temperature $\left(T_{m}\right)$ that results in amplification from gRNA cDNA (or sgRNA cDNA). At this $T_{m}$, DeSCo-PCR should be carried out with an increasing molar ratio of BP to FP to determine the ratio at which there is amplification predominantly from sgRNA cDNA but not (or only faintly) from gRNA cDNA. A positive control with FP plus RP, and a negative control with BP plus RP should be used with both gRNA cDNA and sgRNA cDNA templates to ensure that any lack of amplification is not because of a failed PCR reaction and any successful amplification is not from $B P$, respectively. Next, $T_{m}$ can be finely tuned if required, with the selected BP:FP ratio at which sgRNA cDNA is amplified but amplification from gRNA cDNA is completely blocked. Finally, DeSCo-PCR should be conducted with twofold dilution of sgRNA to determine the lower level of 
detection of sgRNA and the $T_{m}$ can be further fine-tuned accordingly.

To use DeSCo-PCR as a quantitative assay for measuring the relative expression of sgRNA, twofold serial dilutions of sgRNA cDNA can be used as templates for simple- and DeSCo-PCR with varying number of PCR cycles to determine the optimal number of cycles at which DeSCo-PCR reflects the expected sgRNA cDNA dilution.

\section{Proof-of-concept using in vitro transcribed (IVT) gRNA and sgRNA}

To test the concept of DeSCo-PCR, 0.5 pmol each of in vitro transcribed (IVT) RCNMV RNA1, RCNMV SR1f, ZIKV gRNA-mimic1 and ZIKV sfRNA1 were reverse transcribed using either RCNMV reverse primer (RRP) for the RCNMV RNAs or ZIKV reverse primer (ZRP) for the ZIKV RNAs. ZIKV gRNA-mimic1 (Fig. 1B) is a $5^{\prime}$-truncated version of the genomic RNA consisting of the $3^{\prime}$-terminal $1009 \mathrm{nt}$, to serve as a convenient stand-in for full-length ZIKV RNA for initial RT-PCR experiments. cDNA reaction products were diluted fivefold and $2 \mu \mathrm{L}$ of these diluted cDNA reaction products were used as template for PCR.

Simple PCR with RRP plus RCNMV forward primer (RFP) as a positive control amplified both the cDNA from RNA1 (RNA1 cDNA) and cDNA from SR1f (SR1f cDNA), demonstrating successful amplification under PCR conditions (Fig. 3A, lanes 1,4). PCR with RRP plus RCNMV blocking primer (RBP) did not amplify from either RNA1 CDNA or SR $1 f$ cDNA, demonstrating that that RBP is nonextendable under these PCR conditions (Fig. 3A, lanes 2,5). DeSCoPCR with RRP plus RFP plus RBP resulted in amplification only from SR1f cDNA (Fig. 3A, lane 6) but not from RNA1 cDNA (Fig. 3A, lane 3). Similar results were obtained using the ZIKV primers for DeSCo-PCR on the ZIKV RNA templates (Fig. 3B).

It is noteworthy that an unexpected, very low molecular weight band appeared in the $\mathrm{PCR}$ reactions containing $\mathrm{BP}$ (Supplemental Fig. S1). To determine whether it is BP-derived primer-dimer, or if it is a nonspecific amplification product, we conducted PCR with BP plus RP, and FP plus BP plus RP, using sfRNA1 cDNA or water as template. The low molecular weight product appeared, even in the absence of a template, indicating that it is a BP-derived "primer-dimer" (Supplemental Fig. S2, lanes 2,3,5,6). In spite of the presence of primer-dimer, detection of sgRNA and measurement of its relative abundance (below) was not affected.

Additionally, there is a small but reproducible increase in mobility of the DeSCo-PCR product compared to the FPRP PCR product even though both products result from amplification by the FP-RP primer pair (Fig. 3). We found that this difference was due to the presence of the abundant primer-dimer formed only in DeSCo-PCR. We showed this by conducting PCR using ZIKV sfRNA1 cDNA as template with FP plus RP that yields only the band of interest and PCR with BP plus RP that yields only the primer-dimer, mixed these PCR products, and then loaded this mixture in a single well for agarose gel electrophoresis. Mobility of the band of interest from the FP-RP $P C R$, in the presence of the BP + RP primer-dimer, was identical to that from DeSCo-PCR (Supplemental Fig. S2, lanes 1-4). The reason for the slight mobility change due to the primer-dimer is unclear, but it does not affect the utility of DeSCo-PCR.

\section{Quantitative analysis for measuring relative amounts of sgRNA by DeSCo-PCR}

To test if DeSCo-PCR can be used as a quantitative assay for measuring relative amounts of sgRNA, we first tested whether PCR of sgRNA-derived cDNA (in the absence of full-length viral cDNA) was quantitative in the presence of the three primers. In vitro transcribed RCNMV SR1f and ZIKV sfRNA1 were reverse transcribed using RRP and ZRP, respectively, and twofold serial dilutions of the resulting CDNA were used as template for PCR. Relative amounts of sgRNA-derived cDNA in each sample was estimated by measuring the relative intensity of each band with respect to that of undiluted sample. DeSCo-PCR with RRP plus RFP plus RBP showed reduction in band intensity with SR1f cDNA dilution (Fig. 4A). Furthermore, relative band intensity, as measured by DeSCo-PCR, precisely reflected the expected SR1f cDNA dilution (Fig. 4B).

We next tested whether DeSCoPCR can be used as a quantitative assay in the presence of plant total RNA and RCNMV RNA1. Twofold dilutions of IVT SR1f were mixed with a constant amount of $N$. benthamiana total RNA and IVT RCNMV RNA 1 (hence, gRNA and sgRNA are in different 


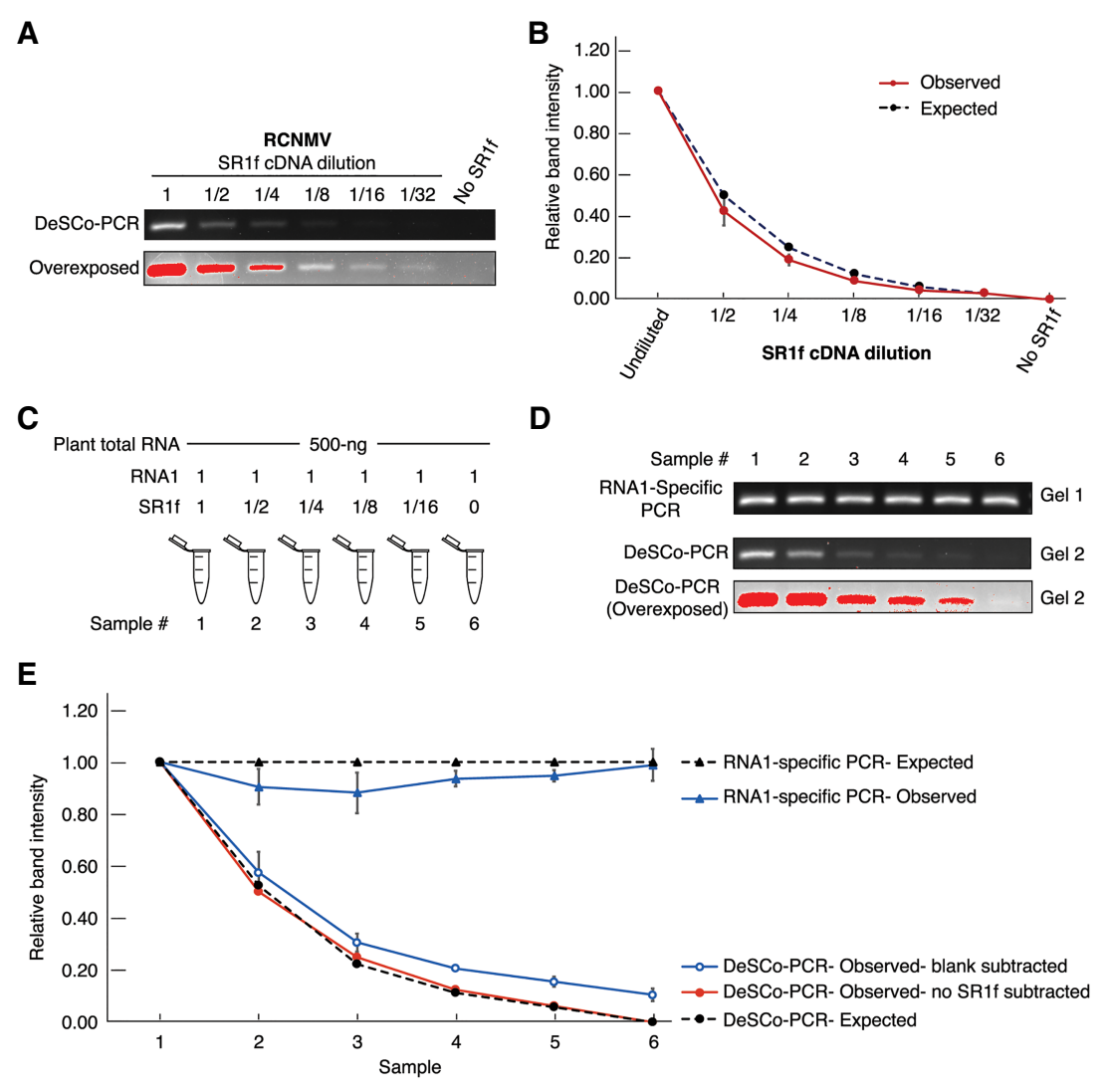

FIGURE 4. Measurement of relative amounts of in vitro transcribed RCNMV SR1f by DeSCoPCR. (A) DeSCo-PCR gel image. (B) Graph of relative amounts of RCNMV SR1f as estimated by relative intensity measurements when only SR1 $\mathrm{fNA}$ was used for CDNA synthesis. 1, 1/2, 1/4, $1 / 8,1 / 16,1 / 32$ denotes the SR1f cDNA dilution, starting with 0.1 pmol of SR1f. (C) Composition of RNA mix for reverse transcription containing dilutions of SR1f in the presence of fixed amounts of RCNMV RNA1 and total plant RNA. 1, 1/2, 1/4, 1/8, 1/16 denotes the SR1f dilution. (D) DeSCo-PCR gel image of dilutions in C. (E) Graph of relative RNA abundance as calculated by measuring the band intensities of the PCR products. Gel1: RNA1-specific PCR (both primers upstream of SR1f sequence), Gel2: DeSCo-PCR. Red bands in the gel images denote saturated pixels from overexposing the gel.

ratios). Five hundred nanograms of $N$. benthamiana total RNA was mixed with 0.1 pmol IVT RNA1 and twofold serial dilutions of IVT SR1f starting with an undiluted amount of 0.1 pmol (Fig. 4C). Subsequently, the RNA mixes were reverse transcribed with RRP followed by PCR. RNA1-specific PCR with RNA1-specific forward primer (RCNMV_909_FP) plus RNA1-specific reverse primer (RCNMV_1262_RP) (both far upstream of the sgRNA region of the genome) showed that the band intensity across all samples was uniform, as expected (Fig. 4D, Gel 1). DeSCo-PCR with RRP plus RFP plus RBP that amplifies only SR1f showed reduction in band intensity with SR1f dilution (Fig. 4D, Gel 2). Relative band intensities were used as proxy for measuring the relative amounts of RNA1 or SR1f. The relative amount of RNA1 was mostly uniform across all samples as measured by RNA1-specific PCR, as expected (Fig. 4E). Relative amounts of SR1f (blank subtracted) from DeSCo-PCR reflected the expected SR1f dilutions (Fig. 4E). Relative band intensity calculation by blank-subtracted values shows that there is either a very small amount of amplification that occurs from RNA1 or it is just the background fluorescence. If relative intensities were calculated using no-SR1f sample subtracted values, the estimation of relative amounts of SR1f became even more accurate (Fig. 4E).

We also tested whether the detection of ZIKV sfRNA1 by DeSCo-PCR was quantitative. As for RCNMV, DeSCo-PCR of dilutions of ZIKV sfRNA1-derived CDNA with ZRP plus ZFP plus ZBP showed a reduction in band intensity proportional to the cDNA dilution (Fig. 5A,B). These results show that DeSCo-PCR can precisely measure relative amounts of sgRNA cDNA.

To test if DeSCo-PCR can be used as a quantitative assay in the presence of ZIKV gRNA, twofold dilutions of IVT sfRNA1, starting at $0.1 \mathrm{pmol}$, were mixed with constant levels $(0.1$ pmol) of IVT gRNA-mimic1 (Fig. 5C). This RNA mix was reverse transcribed with ZRP followed by PCR. gRNA-mimic1-specific PCR with ZIKV gRNA-specific forward primer (ZIKV 9827_FP) plus ZIKV gRNA-specific reverse primer (ZIKV_10115_RP) showed that the band intensity across all samples was uniform, as we observed with RCNMV (Fig. 5D, Gel 1).

DeSCo-PCR with ZRP plus ZFP plus ZBP that amplifies only sfRNA1 showed reduction in band intensity with sfRNA1 dilution (Fig. 5D, Gel 2). The relative amount of gRNA-mimic1 was uniform across all samples as measured by gRNA-mimic1-specific PCR, as expected (Fig. 5E). The relative amount of sfRNA1 (blank subtracted) from DeSCoPCR reflected the expected sfRNA1 dilutions (Fig. 5E). If relative intensities were calculated using no-sfRNA1 sample subtracted values, the estimation of relative amounts of sfRNA1 became even more accurate. Collectively, these experiments show that DeSCo-PCR can quantitatively detect sgRNAs, even in the presence of gRNA, and allow calculation of relative differences in sgRNA/gRNA ratio.

\section{Specific detection of sgRNA in virus-infected tissues}

We next tested whether DeSCo-PCR could distinguish viral genomic from subgenomic RNA in infected tissues. We 


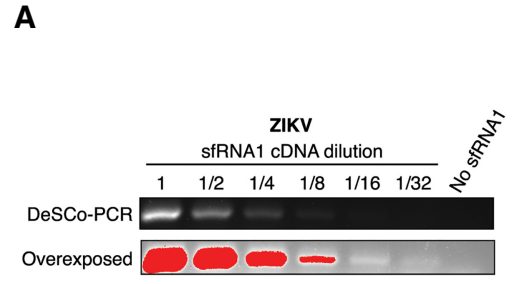

C

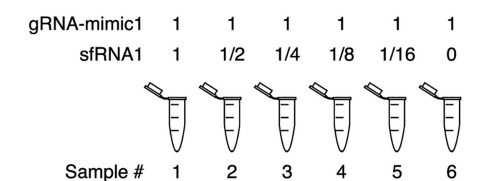

E

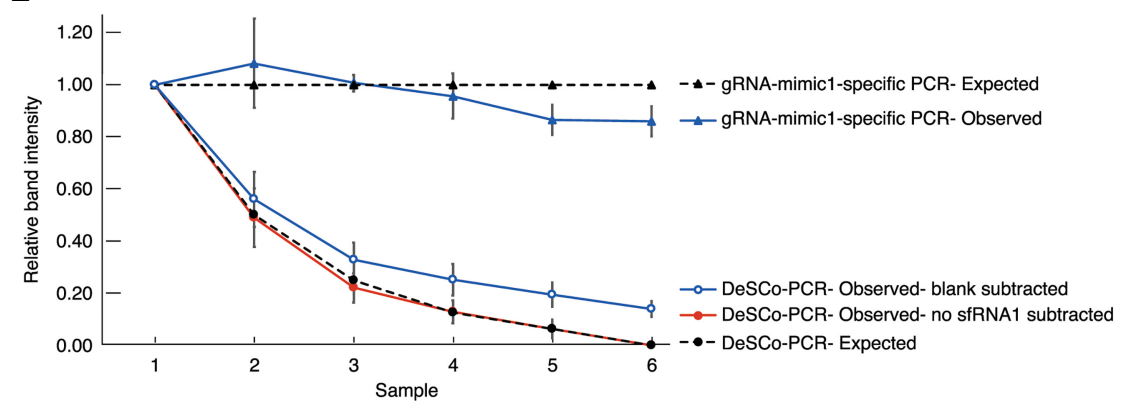

FIGURE 5. Measurement of relative amounts of in vitro transcribed ZIKV sfRNA1 by DeSCoPCR. (A) DeSCo-PCR gel image. (B) Graph of relative amounts of ZIKV sfRNA1 as estimated by relative intensity measurements when only sfRNA1 was used for CDNA synthesis. 1, 1/2, $1 / 4,1 / 8,1 / 16,1 / 32$ denotes the sfRNA1 cDNA dilution, starting with 0.1 pmol of sfRNA. (C) Composition of RNA mix for reverse transcription containing dilutions of sfRNA1 in the presence of fixed amounts of gRNA-mimic1. 1, 1/2, 1/4, 1/8, 1/16 denotes the sfRNA1 dilution. (D) DeSCo-PCR gel image of dilutions in C. (E) Graph of relative RNA abundance as calculated by measuring the band intensities of PCR products. Gel1: gRNA-mimic1-specific PCR (both primers upstream of sfRNA1 sequence), Gel2: DeSCo-PCR. Red bands in the gel images denote saturated pixels from overexposing the gel.

first tested RCNMV (R) in the plant host $N$. benthamiana, taking advantage of a viral mutant (R $\Delta \mathrm{SR} 1 \mathrm{f}$ ) we constructed, which contains a six-base substitution in its xrRNA structure at the $5^{\prime}$ end of the SR1f sequence, preventing it from generating the noncoding subgenomic SR1f RNA (Iwakawa et al. 2008). Northern blot hybridizations with a probe complementary to the $3^{\prime}$ end of RCNMV RNA1 revealed ample amounts of SR1f from $N$. benthamiana plants infected with wild-type RCNMV, and no (or vanishingly small amounts of) SR1f in plants infected with RCNMV $\Delta S R 1 f$, while both sets of plants accumulated substantial amounts of RCNMV genomic RNA1 and CPsgRNA (Fig. 6A). cDNA was prepared from $1 \mu \mathrm{g}$ of total RNA from RCNMV-infected and RCNMV $\Delta$ SR1f-infected $N$. benthamiana leaves using RRP followed by PCR. Because RCNMV $\triangle$ SR1f has a six-base substitution at the $5^{\prime}$ end of the SR1f sequence, forward and BPs incorporating this substitution, RFP-m1 and RBP-m1, respectively, were used for PCR with CDNA from RCNMV $\triangle$ SR1f-infected samples. PCR with RRP plus RFP, and RRP plus RFP-m1 resulted in amplification from both RCNMV-infected and RCNMV $\Delta S R 1$-infected cDNA samples, respectively, confirming successful virus infection (Fig. 6B, L1 and L2). PCR with RRP plus RBP, and RRP plus RBP-m1 primers did not result in amplification showing that the RBP and RBP-m1 are nonextendable under PCR conditions (Fig. 6B, L3 and L4). DeSCo-PCR with RRP plus RFP plus RBP amplified only from RCNMV-infected CDNA samples (Fig. 6B, L5) while DeSCoPCR with RRP plus RFP-m1 plus RBP$\mathrm{m} 1$ resulted in no amplification from RCNMV $\Delta$ SR1f-infected cDNA samples (Fig. 6B, L6) demonstrating that SR1f is detected only in wild-type RCNMV-infected plants and not in RCNMV $\Delta$ SR1f-infected plants.

We next tested ZIKV RNA accumulation in HeLa cells, taking advantage of a mutant, 10 $\mathrm{ZIKV}$ (deletion of nts 10,650 to 10,659 in the $3^{\prime}$ UTR) that produces a lower ratio of sfRNA1/ gRNA than wild-type ZIKV (Shan et al. 2017b). Northern blot hybridization with a 3' probe complementary to ZIKV RNA revealed much greater levels of sfRNA1 in cells infected with wild-type virus than with the mutant. In this case, the genomic RNA levels were also reduced in $10 \Delta \mathrm{ZIKV}$ infection, but the sfRNA1 was virtually undetectable by northern blot hybridization in 10 1 ZIKV-infected cells (Fig. 6C). cDNA was prepared from $1 \mu \mathrm{g}$ total RNA from mock-infect-

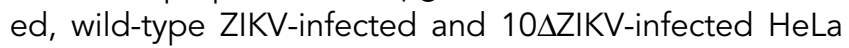
cells using ZRP. PCR of the resulting CDNA template with ZRP plus ZFP primers amplified both ZIKV-infected and 10 $\Delta$ ZIKV-infected cDNA samples, but not from mock-infected cDNA samples, as expected (Fig. 6D, lanes 1-3). There was no amplification using ZRP plus ZBP primer pairs, confirming that the ZBP is nonextendable under the PCR conditions (Fig. 6D, lanes 4,5). DeSCo-PCR with ZRP plus ZFP plus ZBP primers yielded a product from CDNA from cells infected with wild-type ZIKV (Fig. 6D, lane 6), but only a very faint band from 10 ZZIKV-infected cells (Fig. 6D, lane 7), reflecting the ratios of sfRNA1/ gRNA observed by northern blot hybridization and published previously (Shan et al. 2017b). Collectively, these experiments demonstrate that DeSCo-PCR can be used 


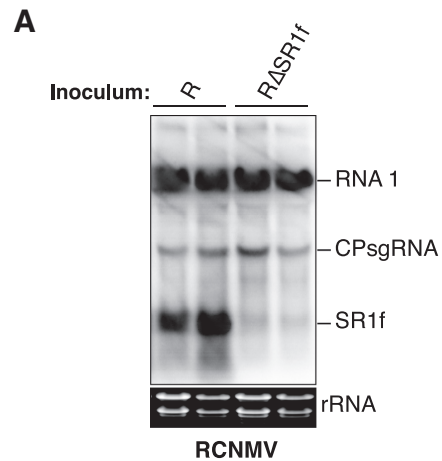

B

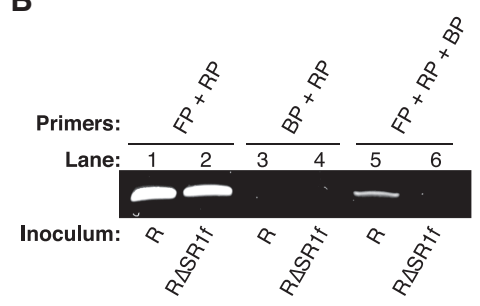

C

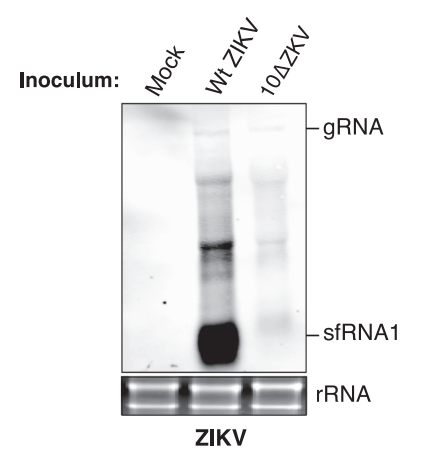

D

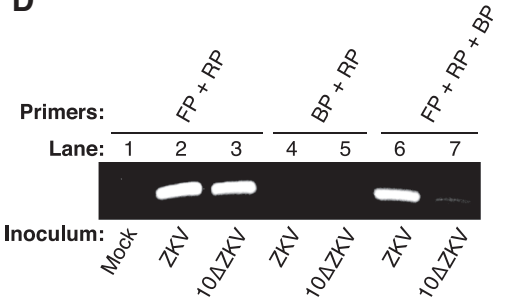

FIGURE 6. Detection of sgRNAs in virus-infected plants or HeLa cells. (A) Northern blot hybridization of total RNA from $N$. benthamiana leaves $14 \mathrm{~d}$ after inoculation with wild-type (R) or mutant (R $\triangle \mathrm{SR} 1 \mathrm{f}$ ) RCNMV. Stained gel shows ribosomal RNA as loading control for each lane. Duplicate samples are shown for each treatment. (B) Detection of SR1f in total RNA from plants infected with indicated wild-type or mutant RCNMV by DeSCo-PCR. Primer combinations used to generate the PCR products are shown above each lane of the gel. (C) Northern blot hybridization of total RNA from HeLa cells $48 \mathrm{~h}$ after inoculation with wildtype $(\mathrm{Wt})$ or mutant $10 \Delta \mathrm{ZIKV}$. Stained gel shows ribosomal RNA as loading control for each lane. (D) Detection of sfRNA1 in total RNA from cells infected with indicated wild-type or mutant ZIKV by DeSCo-PCR. Primer combinations used to generate the PCR products are shown above each lane of the gel. (FP) forward primer, (RP) reverse primer, (BP) blocking primer.

for specific, quantitative detection of sgRNAs from hosts in different kingdoms infected by unrelated viruses.

\section{DISCUSSION}

DeSCo-PCR is a simple, quick, inexpensive and sensitive assay that can selectively amplify a viral sgRNA from a pool of RNA containing host total RNA, viral gRNA and other sgRNAs. Even though northern blot hybridization has certain advantages (e.g., the entire sequence of sgRNA need not be known and it can detect gRNA and multiple sgRNAs simultaneously), DeSCo-PCR can easily detect sgRNAs in a variety of experimental settings to rapidly screen for sgRNA production. Similar to northern blot hybridization, DeSCo-PCR can be used for measuring relative abundance of sgRNAs in different experimental conditions such as those from mutant viral genomes or in transgenic hosts. While it does not measure absolute amounts of RNA, DeSCo-PCR quantitatively measures relative amounts of sgRNA and can detect differences in ratios of sgRNA:gRNA between different virus isolates. The advantages of DeSCo-PCR are particularly beneficial for experiments where several viral mutants or isolates need to be screened rapidly to identify the relative amount of duced as alternatively spliced RNA isoforms. These truncated mRNA isoforms may differ in their $5^{\prime}$ UTR, affecting their stability and translation efficiency or differ in their encoded protein domains, affecting their localization, function and protein stability (RojasDuran and Gilbert 2012; Wang et al. 2016; Galipon et al. 2017). For example in humans, adenosine deaminases acting on RNA (ADARs) are involved in RNA editing, and the ADAR1 gene produces two coterminal mRNA isoforms, ADAR1-p150 and ADAR1-p110 from an interferon-inducible promoter and a constitutive promoter, respectively (Galipon et al. 2017). Additionally, next-generation sequencing and computational analysis are often used to identify, predict functions and determine differential expression of these transcript isoforms with a certain degree of confidence (Kandoi and Dickerson 2017, 2019; Qin et al. 2018). However, these analyses are often followed by molecular assays for validation and DeSCo-PCR provides a simple alternative to northern blot hybridization for confirming the production of a truncated RNA isoform with coterminal ends and measuring their relative abundance.

Because DeSCo-PCR involves competition between blocking and forward primers for selective annealing to gRNA or sgRNA cDNA, it may be possible to design 
TABLE 1. Comparison of northern blot hybridization to DeSCo-PCR

\begin{tabular}{|c|c|c|}
\hline & Northern blot hybridization & DeSCo-PCR \\
\hline Input amount of total RNA & $5-15 \mu g$ & $0.5-2 \mu \mathrm{g}$ \\
\hline Time consumed & $\begin{array}{l}\text { Electrophoresis ( } \sim 2 \mathrm{~h} \text { ) } \\
\text { Transfer to membrane (overnight) } \\
\text { Probe preparation ( } \sim 2 \mathrm{~h} \text { ) } \\
\text { Prehybridization incubation }(\sim 1-2 \mathrm{~h} \text { ) } \\
\text { Probe hybridization (overnight) } \\
\text { Washing ( } \sim 2.5 \mathrm{~h}) \\
\text { Autoradiography (few hours to days) } \\
\text { Clean-up ( 0.5-1 h) }\end{array}$ & $\begin{array}{l}\text { CDNA synthesis ( 1 h) } \\
\text { PCR (1-2 h) } \\
\text { Gel imaging ( 5-10 min) } \\
\text { Clean-up (10 min) }\end{array}$ \\
\hline Hazardous reagents & $\begin{array}{l}\text { Formaldehyde } \\
\text { Radioactive isotope }\end{array}$ & None \\
\hline Sequence information of $5^{\prime}$ end of sgRNA & Not required & Required. But, it can tolerate a few mismatch bases \\
\hline Detect multiple sgRNAs simultaneously & Yes & May be possible with some modifications \\
\hline
\end{tabular}

primers that tolerate a few mismatched bases at the $5^{\prime}$ end of sgRNA in cases where the exact $5^{\prime}$ end nucleotide of the sgRNA has not been determined precisely. Also, it may be possible to use a BP terminating in a dideoxynucleotide (Sanger et al. 1977) to make it universally nonextendable, instead of the mismatched $3^{\prime}$ terminal sequence on our BPs. This may eliminate the production of BP-derived primer-dimer and therefore, make DeSCo-PCR adaptable to gRT-PCR. In addition, a BP with a few locked nucleic acid (LNA) (Koshkin et al. 1998; Ballantyne et al. 2008; Veedu et al. 2008) nucleotides in the BP-CR region would increase its binding affinity to gRNA cDNA, helping BP to out-compete FP for annealing to gRNA cDNA at lower annealing temperatures, which would be more optimal for amplification. However, use of dideoxynucleotides or LNAs would increase primer costs many-fold. Although presently DeSCo-PCR cannot be used for absolute quantification of the number of copies of a sgRNA by qRT-PCR because of amplification of primer-dimer (Supplemental Fig. S1), it can reliably be used to quantitatively compare the relative abundance of sgRNAs of different virus strains or mutants in a highly sensitive manner. Similar to northern blot hybridization, DeSCo-PCR requires some optimization with every virus, but this can be done in a short time (2 or 3 d) (Table 1). In summary, DeSCo-PCR provides a simple, readily optimized, cost-effective method for rapid, sensitive quantification of viral subgenomic RNAs in only a limited amount of total RNA and without the use of expensive and hazardous chemicals.

\section{MATERIALS AND METHODS}

\section{Oligonucleotide synthesis}

All primers were synthesized by Integrated DNA Technologies and purified by standard desalting. Sequences and genomic positions of primers that were used for construction of pRC169c,
pRSR1f, pR1m1，ZIKV gRNA-mimic1 PCR product, and ZIKV sfRNA1 PCR product are listed in Supplemental Table S1. Sequences and genomic positions of primers that were used for all RT-PCR experiments, including DeSCo-PCR, are listed in Supplemental Table S2.

\section{Plasmid construction}

Full-length infectious cDNA clones of RCNMV Australian strain RNA1 (pRC169) and RNA2 (pRC2|G) (Xiong and Lommel 1991; Sit et al. 1998) were kindly provided by Dr. Tim L. Sit and Dr. S. A. Lommel. pRC169 and pRC2|G are cDNA clones with a T7-promoter for in vitro transcription of infectious RNA1 and RNA2, respectively. pRC169 was sequenced by Sanger sequencing and was found to contain several base changes compared to the sequence from NCBI (GenBank: J04357). Two of the base changes, at positions 3462 and 3494, were present near the $5^{\prime}$ end of SR1f and therefore, were changed from $\mathrm{C}$ to $\mathrm{T}$ and $\mathrm{G}$ to $\mathrm{A}$, respectively, using Q5 Site-Directed Mutagenesis kit (NEB \#E0554) according to manufacturer's protocol with primers 3UTR_R1_corrected_for and 3UTR_R1_corrected_rev. The corrected plasmid, pRC169c, was used as template for construction of pRSR1f and pR1m1, and as template for in vitro transcription of infectious RCNMV RNA1.

\section{pRSR1f}

pRSR1f is a cDNA clone with T7-promoter followed by SR1f sequence for in vitro transcription of SR1f. A Q5 Site-Directed Mutagenesis kit (NEB \#E0554) was used according to manufacturer's protocol. A DNA fragment with the T7 promoter sequence, vector sequence and SR1f sequence was amplified from pRC169c with the following PCR reaction composition and conditions: Q5-hot start high fidelity $2 \times$ master mix $(1 \times)$, T7-rev primer $(0.5 \mu \mathrm{M})$, SR1f_for primer $(0.5 \mu \mathrm{M})$, pRC169c as template (10 ng); initial denaturation at $98^{\circ} \mathrm{C}$ for $30 \mathrm{sec} ; 25$ cycles of denaturation at $98^{\circ} \mathrm{C}$ for $10 \mathrm{sec}$, annealing at $60^{\circ} \mathrm{C}$ for $30 \mathrm{sec}$, extension at $72^{\circ} \mathrm{C}$ for $2.5 \mathrm{~min}$; final extension at $72^{\circ} \mathrm{C}$ for $2 \mathrm{~min}$. This was followed by ligation, according to manufacturer's protocol, to circularize the PCR product. Subsequently, the plasmid was transformed in 
E. coli sigma 10 cells and colonies were screened in LB-agar plates with ampicillin. Plasmids were extracted from selected colonies and the sequence was verified by Sanger sequencing.

\section{pR1m1}

$\mathrm{pR} 1 \mathrm{~m} 1$ is an infectious cDNA clone of RCNMV RNA1 (RNA1-m1) that does not generate SR1f during infection. pR1m1 has a sixbase substitution ("TGTAGC" to "ACGTTG") in pRC169c (nts 3462 to 3467 ) that disrupts the xrRNA structure required for SR1f production (Iwakawa et al. 2008). A Q5 Site-Directed Mutagenesis kit (NEB \#E0554) was used according to manufacturer's protocol. The DNA fragment was amplified by PCR with the following reaction composition and conditions: Q5-hot start high fidelity $2 \times$ master mix $(1 \times)$, SR1f.m1_for primer $(0.5 \mu \mathrm{M})$, SR1f.m1_rev primer $(0.5 \mu \mathrm{M})$, pRC169c as template (10 ng); initial denaturation at $98^{\circ} \mathrm{C}$ for $30 \mathrm{sec} ; 25$ cycles of denaturation at $98^{\circ} \mathrm{C}$ for $10 \mathrm{sec}$, annealing at $59^{\circ} \mathrm{C}$ for $30 \mathrm{sec}$, extension at $72^{\circ} \mathrm{C}$ for 4 min; final extension at $72^{\circ} \mathrm{C}$ for $2 \mathrm{~min}$. This was followed by ligation, according to manufacturer's protocol, to circularize the PCR product. Subsequently, the plasmid was transformed in $E$. coli sigma 10 cells and colonies were screened in LB-agar plates with ampicillin. Plasmids were extracted from selected colonies and the sequence was verified by Sanger sequencing.

All RCNMV cDNA clones were linearized at a unique Smal restriction site at the precise $3^{\prime}$ end of the RCNMV 3' UTR prior to in vitro transcription.

\section{ZIKV gRNA-mimic1 PCR product}

ZIKV gRNA-mimic1 PCR product is a DNA fragment with a T7 promoter followed by a partial sequence of ZIKV gRNA (nts 9799 to 10807). It was amplified from pFLZIKV (Shan et al. 2016) using the primers NS5 (+) forward primer 1 and sfRNA (-) reverse primer. ZIKV gRNA-mimic1 PCR product was used for in vitro transcription to make noninfectious ZIKV gRNA-mimic1 that was used for DeSCo-PCR experiments.

\section{ZIKV sfRNA1 PCR product}

ZIKV sfRNA1 PCR product is a DNA fragment with a T7-promoter followed by the sequence of ZIKV sfRNA1 (nts 10392 to 10807). It was amplified from pFLZIKV (Shan et al. 2016) using the primers sfRNA (+) forward primer and sfRNA (-) reverse primer. ZIKV sfRNA1 PCR product was used for in vitro transcription to make ZIKV sfRNA1 that was used for DeSCo-PCR experiments.

\section{In vitro transcription}

One $\mu \mathrm{g}$ linearized plasmid for all RCNMV constructs, $200 \mathrm{ng}$ ZIKV sfRNA1 PCR product, and 500 ng ZIKV gRNA mimic1 PCR product were used as templates for in vitro transcription using MEGAscript T7 Transcription kit (Invitrogen \#AM1334) followed by DNase treatment according to manufacturer's protocol. The transcription reaction was carried out at $37^{\circ} \mathrm{C}$ for $4 \mathrm{~h}$ and DNase treatment at $37^{\circ} \mathrm{C}$ for $30 \mathrm{~min}$. Subsequently, RNA was purified using Zymo RNA Clean \& Concentrator -5 kit (Zymo Research \#R1015) and eluted in nuclease-free water.

\section{Virus inoculation and RNA extraction}

\section{RCNMV}

Nicotiana benthamiana plants at the four-leaf stage were used for inoculations. Two leaves per plant were inoculated. Per leaf, $1 \mu \mathrm{g}$ in vitro-transcribed (IVT) RCNMV RNA1 plus $1 \mu \mathrm{g}$ IVT RCNMV RNA2 were mixed in $10 \mathrm{mM}$ sodium phosphate buffer $(\mathrm{pH}$ 6.8) and rubbed on the leaves. These are referred to as RCNMV-infected plants that make SR1f. Similarly, $1 \mu \mathrm{g}$ IVT RCNMV RNA1$\mathrm{m} 1$ plus $1 \mu \mathrm{g}$ IVT RCNMV RNA2 were mixed in $10 \mathrm{mM}$ sodium phosphate buffer ( $\mathrm{pH}$ 6.8) and rubbed on the leaves. These are referred to as RCNMV $\triangle S R 1$ f-infected plants that do not make SR1f. For Figure 6, leaves from RCNMV- and RCNMV $\triangle$ SR1f-infected $N$. benthamiana were collected at $5 \mathrm{~d}$ post inoculation (dpi) for PCR and at 14 dpi for northern blot hybridization, pulverized and total RNA was extracted using Zymo Direct-zol RNA Miniprep (Zymo Research \#R2051).

\section{ZIKV}

Hela cells were seeded at a density of $3 \times 10^{5}$ cells per well in a sixwell plate. One day later, cells were infected with the wild-type (ZIKV-Cambodia) or mutant (10 $\Delta$ ZIKV) virus at an $\mathrm{MOI}$ of 3. After $48 \mathrm{~h}$ post-infection, cells were washed with PBS and total RNA was extracted from cells using the Direct-zol RNA MiniPrep kit (Zymo Research).

\section{cDNA synthesis}

Amount of in vitro transcribed RNA or plant/cell total RNA that were reverse transcribed is indicated in the results section. RNA (IVT or total RNA) and virus-specific reverse primer (15 pmol; same reverse primer as used for DeSCo-PCR) were mixed in nuclease-free water to $12 \mu \mathrm{L}$ and incubated at $65^{\circ} \mathrm{C}$ for $5 \mathrm{~min}$, transferred to ice followed by addition of $4 \mu \mathrm{L}$ reaction buffer, $1 \mu \mathrm{L}$ RiboLock, $2 \mu \mathrm{L} 10 \mathrm{mM}$ dNTPs and $1 \mu \mathrm{L}$ RT enzyme from RevertAid First Strand cDNA Synthesis kit (Thermo Scientific \#K1621). The reaction mix was incubated at $42^{\circ} \mathrm{C}$ for $60 \mathrm{~min}$ followed by enzyme deactivation at $70^{\circ} \mathrm{C}$ for $5 \mathrm{~min}$. The cDNA reaction products from IVT RNAs were diluted fivefold and considered as "undiluted samples" for experiments with serially diluted templates while cDNA reaction products from total RNA from infected samples were not diluted but used as is for PCR.

\section{PCR}

GoTaq G2 green master mix (Promega \#M7823) was used for all PCR reactions. Simple PCR with RP plus FP as positive control, RP plus BP as negative control, DeSCo-PCR with RP plus FP plus BP, and gRNA-specific PCR were carried out in a thermocycler with the capability of controlling the ramp rate. Ramp rate of $0.5^{\circ} \mathrm{C}$ per second was used for the PCR reactions specified below. A $20 \mu \mathrm{L}$ PCR reaction mix was prepared with $2-\mu \mathrm{L}$ template and final concentration of each of the primers, if used, were as follows: 0.2 $\mu \mathrm{M}$ RP, $0.2 \mu \mathrm{M} \mathrm{FP}, 4 \mu \mathrm{M}$ BP. BP: FP = 20: 1 was determined, empirically, as optimum for RCNMV and ZIKV, for successful DeSCoPCR to selectively amplify sgRNA cDNA and completely block amplification from gRNA cDNA (data not shown). The primers 
used are mentioned below and the primer sequences can be found in Supplemental Table S2. PCR conditions were as follows:

\section{RCNMV}

$98^{\circ} \mathrm{C}(2 \mathrm{~min}) ; 18$ cycles of $98^{\circ} \mathrm{C}(30 \mathrm{sec}), 65^{\circ} \mathrm{C}(20 \mathrm{sec}$, ramp rate $=$ $\left.0.5^{\circ} \mathrm{C} / \mathrm{sec}\right), 72^{\circ} \mathrm{C}(30 \mathrm{sec}) ; 72^{\circ} \mathrm{C}(2 \mathrm{~min}) ; 4^{\circ} \mathrm{C}$ hold. Primers used were RFP, RRP, RBP, RFP-m1, and RBP-m1.

\section{RCNMV (RNA1-specific PCR)}

$98^{\circ} \mathrm{C}(2 \mathrm{~min}) ; 18$ cycles of $98^{\circ} \mathrm{C}(30 \mathrm{sec}), 60^{\circ} \mathrm{C}(20 \mathrm{sec}), 72^{\circ} \mathrm{C}$ (30 sec); $72^{\circ} \mathrm{C}(2 \mathrm{~min}) ; 4^{\circ} \mathrm{C}$ hold. Primers used were RCNMV_909_FP and RCNMV_1262_RP.

\section{ZIKV (with IVT templates)}

$98^{\circ} \mathrm{C}(2 \mathrm{~min}) ; 22$ cycles of $98^{\circ} \mathrm{C}(30 \mathrm{sec}), 66.5^{\circ} \mathrm{C}$ ( $20 \mathrm{sec}$, ramp rate $\left.=0.5^{\circ} \mathrm{C} / \mathrm{sec}\right), 72^{\circ} \mathrm{C}(40 \mathrm{sec}) ; 72^{\circ} \mathrm{C}(2 \mathrm{~min}) ; 4^{\circ} \mathrm{C}$ hold. Primers used were ZFP, ZRP, and ZBP. ZIKV gRNA-specific PCR was carried out in the same conditions as above with primers ZKV_9827_FP and ZKV_10115_RP.

\section{ZIKV (with infected samples as templates)}

$98^{\circ} \mathrm{C}(2 \mathrm{~min}) ; 30$ cycles of $98^{\circ} \mathrm{C}(30 \mathrm{sec}), 65^{\circ} \mathrm{C}(20 \mathrm{sec}$, ramp rate $=$ $\left.0.5^{\circ} \mathrm{C}\right), 72^{\circ} \mathrm{C}(40 \mathrm{sec}) ; 72^{\circ} \mathrm{C}(2 \mathrm{~min}) ; 4^{\circ} \mathrm{C}$ hold. Primers used were ZFP, ZRP, and ZBP.

PCR reaction products were run on a $1 \%$ agarose gel, with SYBR Safe DNA gel stain (Invitrogen \#S33102), in 1× TBE buffer and visualized on a Bio-Rad Gel doc. The gel images shown were cropped to show the band of interest. One thing to note is that all DeSCo-PCR performed with RCNMV and ZIKV resulted in amplification of BP-derived primer-dimer but it did not affect the relative band intensity measurement.

\section{Measurement of relative expression of sgRNA}

When the agarose gels were imaged for quantitative analysis, the exposure time was set for maximum duration at which no saturating intensity was observed in the amplified bands. Fiji software (ImageJ) was used to measure band intensity. Intensity of the background was measured from three separate regions of the gel where no band/DNA is expected, and the values were averaged. The averaged background intensity, referred to as "blank," was subtracted from the intensity of each band from gRNA-specific PCR. For DeSCo-PCR, either the "blank" values or the band intensity of "No sgRNA" samples were considered as background intensity and were subtracted from the band intensity of each sample. This was done three times for each gel and background-subtracted values from the three measurements were averaged. The final values were normalized with respect to the band intensity of undiluted cDNA. The values obtained from DeSCo$P C R$ are the relative band intensity representing the relative amount of sgRNA in each sample. For all results shown with the relative measurement of sgRNA, PCR was carried out three times and the values for the relative band intensities were averaged and plotted on a graph using Microsoft Excel. Error bars represent the standard deviation of the relative band intensities obtained from three PCR reactions.

\section{Radiolabeled RNA probe preparation}

A DNA template with SP6-promoter for transcribing a radiolabeled RNA probe that can hybridize to a positive sense strand of RCNMV RNA1 3' UTR (nts 3605 to 3800 ) was prepared by PCR with the following composition and conditions: An amount of $50 \mu \mathrm{L}$ reaction with GoTaq G2 green master mix (1×), R1.3UTR. for (0.2 $\mu \mathrm{M}, 5^{\prime}$-TCG GAC CCT GGG AAA CAG GT-3'), R1.3UTR. SP6.rev (0.2 $\mu \mathrm{M}$, 5'-GATATTTAGGTGACACTATAGAGGTATG CGCCCTCTGAGC-3'), pRC169 as template (10 ng); initial denaturation at $95^{\circ} \mathrm{C}$ for $2 \mathrm{~min}$; 25 cycles of denaturation at $95^{\circ} \mathrm{C}$ for $30 \mathrm{sec}$, annealing at $56^{\circ} \mathrm{C}$ for $30 \mathrm{sec}$, extension at $72^{\circ} \mathrm{C}$ for 30 sec; final extension at $72^{\circ} \mathrm{C}$ for $5 \mathrm{~min}$. The underlined bases in the primer sequence represent SP6 promoter sequence. The amplified product was purified using QIAquick PCR Purification kit (Qiagen \#28104) and used as a template for making a radiolabeled probe using MEGAscript SP6 Transcription kit (Invitrogen \#AM1330) with the following reaction composition: An amount of $2 \mu \mathrm{L} 10 \times$ reaction buffer, $2 \mu \mathrm{L} 5 \mathrm{mM}$ AUG mix, $2.5 \mu \mathrm{L} 0.1 \mathrm{mM}$ CTP, 50 ng DNA template, $0.5 \mu \mathrm{L}$ RNase OUT (Invitrogen \#10777019), $2 \mu \mathrm{L}$ SP6 enzyme, $2.5 \mu \mathrm{L}$ CTP (a- ${ }^{32} \mathrm{P}$; PerkinElmer \#BLU008X250UC). The reaction was incubated at $37^{\circ} \mathrm{C}$ for $3 \mathrm{~h}$ followed by DNase treatment with $1 \mu \mathrm{L}$ Turbo DNase at $37^{\circ} \mathrm{C}$ for 15 min and a radiolabeled RNA probe was purified using Micro Biospin 30 columns (Bio-Rad \#732-6251) and stored at $-20^{\circ} \mathrm{C}$.

\section{Northern blot hybridization}

\section{RCNMV}

An amount of $9.5 \mu \mathrm{g}$ total RNA from noninoculated leaves of RCNMV- and RCNMV $\triangle S R 1$-infected $N$. benthamiana were mixed with an equal volume of $2 \times$ RNA loading dye (NEB \#B0363S), denatured by incubating at $70^{\circ} \mathrm{C}$ for $10 \mathrm{~min}$ and 5 min on ice and loaded on a $1.2 \%$ agarose-formaldehyde gel (1.2\% [w/v] agarose, $20 \mathrm{mM}$ sodium phosphate buffer [pH 6.8], $8 \mathrm{~mL}$ of $37 \%$ formaldehyde per $100 \mathrm{~mL}$ of gel). Electrophoresis was carried out at $100 \mathrm{~V}$ for $2 \mathrm{~h}$ in running buffer $(74 \mathrm{~mL}$ of $37 \%$ formaldehyde per $1 \mathrm{~L}$ of running buffer, $20 \mathrm{mM}$ sodium phosphate buffer [pH 6.8]). Integrity and equal loading of RNA were verified by visualizing the gel on a Bio-Rad Gel doc. The gel was washed in sterile water for $5 \mathrm{~min}$ at room temperature (RT) and blotted to a nitrocellulose membrane by the capillary transfer method overnight using 10x saline-sodium citrate (SSC) buffer (Invitrogen \#AM9763). Post-transfer, the membrane was washed in $5 \times$ SSC for 5 min at RT, dried on a paper towel, and UV-crosslinked in StrataGene UV Stratalinker 1800 using the "Auto Cross Link" option. The membrane was placed in a glass cylindrical bottle and incubated in $5 \mathrm{~mL}$ hybridization buffer ( $50 \%$ [v/v] formamide, $5 \times$ SSC buffer, $0.2 \mathrm{mg} / \mathrm{mL}$ polyanetholsulphonic acid, $0.1 \%$ [w/v] SDS, $20 \mathrm{mM}$ sodium phosphate buffer $\left[\mathrm{pH} \mathrm{6.8])} \mathrm{at} 65^{\circ} \mathrm{C}\right.$ for $1 \mathrm{~h}$ in a hybridization oven (VWR). The buffer was discarded, and fresh $5 \mathrm{~mL}$ hybridization buffer was added to the bottle with $5 \mu \mathrm{L}$ radiolabeled RNA probe. Probe hybridization was carried out overnight in a hybridization oven at $65^{\circ} \mathrm{C}$. Post hybridization washes were carried out in a hybridization oven as follows: two washes with $50 \mathrm{~mL}$ high salt concentration buffer (1 $\times$ SSC, $0.1 \%$ [w/v] SDS) at RT for $20 \mathrm{~min}$, two washes with $50 \mathrm{~mL}$ low salt concentration buffer $(0.2 \times \mathrm{SSC}, 0.1 \%[\mathrm{w} / \mathrm{v}] \mathrm{SDS})$ at $68^{\circ} \mathrm{C}$ for 
$20 \mathrm{~min}$, and one wash with $50 \mathrm{~mL} 0.1 \times$ SSC buffer at RT for $20 \mathrm{~min}$. The membrane was dried on a paper towel, covered in a saran wrap and placed inside the phosphor cassette with phosphor screen, imaged by autoradiography using Bio-Rad PharosFX Plus Molecular Imager.

\section{ZIKV}

An amount of $5 \mu \mathrm{g}$ of total RNA from mock and ZIKV-infected cells was mixed with $2 \times$ formaldehyde loading buffer (Thermo Fisher Scientific), and denatured by incubating at $65^{\circ} \mathrm{C}$ for $15 \mathrm{~min}$ and 2 min on ice. Electrophoresis was performed in 1\% denaturing agarose gel and stained with ethidium bromide. After electrophoresis, the gel was incubated in the alkaline buffer $(0.01 \mathrm{~N} \mathrm{NaOH}$, $3 \mathrm{M} \mathrm{NaCl}$ ) for 20 min and subsequently transferred to a Biodyne $\mathrm{B}$ nylon membrane (Thermo Fisher Scientific) by upward transfer. The membrane was crosslinked using a UV Stratalinker and blocked at $42^{\circ} \mathrm{C}$ using ULTRAhyb Oligo hybridization for $1 \mathrm{~h}$ while rotating. Blots were probed overnight rotating at $42^{\circ} \mathrm{C}$ with a Biotin-labeled DNA probe prepared as described in SotoAcosta et al. (2018). After hybridization, the membrane was washed in wash buffer for $15 \mathrm{~min}$ at $42^{\circ} \mathrm{C}$ four times. The blot was incubated for $1 \mathrm{~h}$ at room temperature with IRDYE $800 \mathrm{CW}$ streptavidin (LI-COR Biosciences) in Odyssey Blocking Buffer (LICOR Biosciences) with $1 \%$ of SDS. Later the membrane was washed three times with TBS buffer containing $0.1 \%$ tween, and the membrane was scanned using an LI-COR Odyssey.

\section{SUPPLEMENTAL MATERIAL}

Supplemental material is available for this article.

\section{ACKNOWLEDGMENTS}

We thank Dr. Tim L. Sit and Dr. S.A. Lommel for providing us with RCNMV clones, Dr. Surapathrudu Kanakala for his support, critique, and advice on developing the method, and Dr. Steve Whitham for advising on the manuscript. This work was supported by lowa State University Plant Sciences Institute Faculty Scholar award (W.A.M.); National Institute of General Medical Sciences (grant number R01 GM067104) (W.A.M.); start-up funds from the University of Texas Medical Branch and a University of Texas STARs Award (M.A.G.B.); and financial support from Comité para el Desarrollo de la Investigación of University of Antioquia/ Grant 2014-1041 (V.C.R.L.).

Author contributions: P.K. conceptualized the method and conducted all experiments excluding ZIKV template construction, ZIKV infections, and ZIKV northern blot hybridization. K.R.P. conducted ZIKV infections and northern blot hybridization. V.C.R.L. constructed ZIKV templates for in vitro transcription. P.K. and W.A.M. designed the experiments and wrote the draft manuscript. All authors edited the manuscript. W.A.M. supervised P.K., and S.S.B. and M.A.G.B. supervised V.C.R.L. and K.R.P.

Received January 27, 2020; accepted March 26, 2020.

\section{REFERENCES}

Akiyama BM, Laurence HM, Massey AR, Costantino DA, Xie X, Yang Y, Shi P-Y, Nix JC, Beckham JD, Kieft JS. 2016. Zika virus produces noncoding RNAs using a multi-pseudoknot structure that confounds a cellular exonuclease. Science 354: 1148-1152. doi:10 $.1126 /$ science.aah3963

Amiss T, Presnell SC. 2005. Nucleic acid blotting techniques: theory and practice. In Molecular diagnostics: for the clinical laboratorian (ed. Coleman WB, Tsongalis GJ), pp. 31-46. Humana Press, Totowa, NJ.

Ballantyne KN, van Oorschot RAH, Mitchell RJ. 2008. Locked nucleic acids in PCR primers increase sensitivity and performance. Genomics 91: 301-305. doi:10.1016/j.ygeno.2007.10.016

Beckham JD, Pastula DM, Massey A, Tyler KL. 2016. Zika virus as an emerging global pathogen: neurological complications of zika virus. JAMA Neurol 73: 875-879. doi:10.1001/jamaneurol.2016 .0800

Bidet K, Garcia-Blanco MA. 2014. Flaviviral RNAs: weapons and targets in the war between virus and host. Biochem J 462: 215230. doi:10.1042/BJ20140456

Bidet K, Dadlani D, Garcia-Blanco MA. 2014. G3BP1, G3BP2 and CAPRIN1 are required for translation of interferon stimulated mRNAs and are targeted by a dengue virus non-coding RNA. PLoS Pathog 10: e1004242. doi:10.1371/journal.ppat.1004242

Contigiani MS, Diaz LA. 2017. Togaviridae. In Arthropod borne diseases (ed. Marcondes CB), pp. 115-135. Springer International Publishing, Cham.

Donald CL, Brennan B, Cumberworth SL, Rezelj WV, Clark JJ, Cordeiro MT, Freitas de Oliveira França R, Pena LJ, Wilkie GS, Da Silva Filipe A, et al. 2016. Full genome sequence and sfRNA interferon antagonist activity of zika virus from Recife, Brazil. PLoS Negl Trop Dis 10: e0005048. doi:10.1371/journal.pntd.0005048

Ferraris P, Yssel H, Missé D. 2019. Zika virus infection: an update. Microbes Infect 21: 353-360. doi:10.1016/j.micinf.2019.04.005

Finol E, Ooi EE. 2019. Evolution of subgenomic RNA shapes dengue virus adaptation and epidemiological fitness. iScience 16: 94-105. doi:10.1016/j.isci.2019.05.019

Flobinus A, Hleibieh K, Klein E, Ratti C, Bouzoubaa S, Gilmer D. 2016. A viral noncoding RNA complements a weakened viral RNA silencing suppressor and promotes efficient systemic host infection. Viruses 8: 272. doi:10.3390/v8100272

Flobinus A, Chevigny N, Charley PA, Seissler T, Klein E, BleykastenGrosshans C, Ratti C, Bouzoubaa S, Wilusz J, Gilmer D. 2018. Beet necrotic yellow vein virus noncoding RNA production depends on a $5^{\prime} \rightarrow 3^{\prime} \mathrm{Xrn}$ exoribonuclease activity. Viruses 10: 137. doi:10.3390/v10030137

Galipon J, Ishii R, Suzuki Y, Tomita M, Ui-Tei K. 2017. Differential binding of three major human ADAR isoforms to coding and long noncoding transcripts. Genes (Basel) 8: 68. doi:10.3390/ genes8020068

Göertz GP, Fros JJ, Miesen P, Vogels CBF, van der Bent ML, Geertsema C, Koenraadt CJM, van Rij RP, van Oers MM, Pijlman GP. 2016. Noncoding subgenomic flavivirus RNA is processed by the mosquito RNA interference machinery and determines West Nile virus transmission by Culex pipiens mosquitoes. J Virol 90: 10145-10159. doi:10.1128/JVI.00930-16

Gould AR, Francki RIB, Hatta T, Hollings M. 1981. The bipartite genome of red clover necrotic mosaic virus. Virology 108: 499506. doi:10.1016/0042-6822(81)90457-8

Hiruki C. 1987. The dianthoviruses: a distinct group of isometric plant viruses with bipartite genome. Adv Virus Res 33: 257-300. doi:10 .1016/S0065-3527(08)60320-6

Iwakawa HO, Mizumoto H, Nagano H, Imoto Y, Takigawa K, Sarawaneeyaruk S, Kaido M, Mise K, Okuno T. 2008. A viral noncoding RNA generated by cis-element-mediated protection 
against $5^{\prime} \rightarrow 3^{\prime}$ RNA decay represses both cap-independent and cap-dependent translation. J Virol 82: 10162-10174. doi:10 .1128/JVI.01027-08

Kandoi G, Dickerson JA. 2017. Differential alternative splicing patterns with differential expression to computationally extract plant molecular pathways. In 2017 IEEE International Conference on Bioinformatics and Biomedicine (BIBM), pp. 2163-2170, IEEE, NY.

Kandoi G, Dickerson JA. 2019. Tissue-specific mouse mRNA isoform networks. Sci Rep 9: 13949. doi:10.1038/s41598-019-50119-x

Kessler C, Höltke H-J, Seibl R, Burg J, Mühlegger K. 1990. Non-radioactive labeling and detection of nucleic acids. I. A novel DNA labeling and detection system based on digoxigenin: antidigoxigenin ELISA principle (Digoxigenin System). Biol Chem Hoppe Seyler 371: 917-928. doi:10.1515/bchm3.1990.371.2.917

Koev G, Miller WA. 2000. A positive-strand RNA virus with three very different subgenomic RNA promoters. J Virol 74: 5988-5996. doi:10.1128/JVI.74.13.5988-5996.2000

Koshkin AA, Singh SK, Nielsen P, Rajwanshi VK, Kumar R, Meldgaard M, Olsen CE, Wengel J. 1998. LNA (locked nucleic acids): synthesis of the adenine, cytosine, guanine, 5-methylcytosine, thymine and uracil bicyclonucleoside monomers, oligomerisation, and unprecedented nucleic acid recognition. Tetrahedron 54: 3607-3630. doi:10.1016/S0040-4020(98) 00094-5

Lee J, Shin O, Lee JK, Shin OS. 2019. Advances in Zika virus-host cell interaction: current knowledge and future perspectives. Int J Mol Sci 20: 1101. doi:10.3390/ijms20051101

Manokaran G, Finol E, Wang C, Gunaratne J, Bahl J, Ong EZ, Tan HC, Sessions OM, Ward AM, Gubler DJ, et al. 2015. Dengue subgenomic RNA binds TRIM25 to inhibit interferon expression for epidemiological fitness. Science 350: 217-221. doi:10.1126/science .aab3369

Miller WA, Koev G. 2000. Synthesis of subgenomic RNAs by positivestrand RNA viruses. Virology 273: 1-8. doi:10.1006/viro.2000 .0421

Miller WA, Jackson J, Feng Y. 2015. Cis- and trans-regulation of luteovirus gene expression by the $3^{\prime}$ end of the viral genome. Virus Res 206: 37-45. doi:10.1016/j.virusres.2015.03.009

Miller WA, Shen R, Staplin W, Kanodia P. 2016. Noncoding RNAs of plant viruses and viroids: sponges of host translation and RNA interference machinery. Mol Plant-Microbe Interact 29: 156-164. doi:10.1094/MPMI-10-15-0226-FI

Monroe SS, Jiang B, Stine SE, Koopmans M, Glass RI. 1993. Subgenomic RNA sequence of human astrovirus supports classification of Astroviridae as a new family of RNA viruses. J Virol 67: 3611-3614. doi:10.1128/JVI.67.6.3611-3614.1993

Moon SL, Anderson JR, Kumagai Y, Wilusz CJ, Akira S, Khromykh AA, Wilusz J. 2012. A noncoding RNA produced by arthropod-borne flaviviruses inhibits the cellular exoribonuclease XRN1 and alters host mRNA stability. RNA 18: 2029-2040. doi:10.1261/rna .034330 .112

Moon SL, Dodd BJT, Brackney DE, Wilusz CJ, Ebel GD, Wilusz J. 2015. Flavivirus sfRNA suppresses antiviral RNA interference in cultured cells and mosquitoes and directly interacts with the RNAi machinery. Virology 485: 322-329. doi:10.1016/j.virol 2015.08.009

Peltier C, Klein E, Hleibieh K, D'Alonzo M, Hammann P, Bouzoubaa S, Ratti C, Gilmer D. 2012. Beet necrotic yellow vein virus subgenomic RNA3 is a cleavage product leading to stable non-coding RNA required for long-distance movement. J Gen Virol 93: 1093-1102. doi:10.1099/vir.0.039685-0

Pijlman GP, Funk A, Kondratieva N, Leung J, Torres S, van der Aa L, Liu WJ, Palmenberg AC, Shi P-Y, Hall RA, et al. 2008. A highly structured, nuclease-resistant, noncoding RNA produced by flaviviruses is required for pathogenicity. Cell Host Microbe 4: 579591. doi:10.1016/j.chom.2008.10.007
Qin Z, Stoilov P, Zhang X, Xing Y. 2018. SEASTAR: systematic evaluation of alternative transcription start sites in RNA. Nucleic Acids Res 46: e45. doi:10.1093/nar/gky053

Roby JA, Pijlman GP, Wilusz J, Khromykh AA. 2014. Noncoding subgenomic flavivirus RNA: multiple functions in West Nile virus pathogenesis and modulation of host responses. Viruses 6: 404-427. doi:10.3390/v6020404

Rojas-Duran MF, Gilbert W V. 2012. Alternative transcription start site selection leads to large differences in translation activity in yeast. RNA 18: 2299-2305. doi:10.1261/rna.035865.112

Royall E, Locker N. 2016. Translational control during calicivirus infection. Viruses 8: 104. doi:10.3390/v8040104

Sanger F, Nicklen S, Coulson AR. 1977. DNA sequencing with chainterminating inhibitors. Proc Natl Acad Sci 74: 5463-5467. doi:10 $.1073 /$ pnas.74.12.5463

Scheets K. 2000. Maize chlorotic mottle machlomovirus expresses its coat protein from a 1.47-kb subgenomic RNA and makes a 0.34-kb subgenomic RNA. Virology 267: 90-101. doi:10.1006/viro.1999 .0107

Schnettler E, Sterken MG, Leung JY, Metz SW, Geertsema C, Goldbach RW, Vlak JM, Kohl A, Khromykh AA, Pijlman GP. 2012. Noncoding flavivirus RNA displays RNA interference suppressor activity in insect and mammalian cells. J Virol 86: 1348613500. doi:10.1128/JVI.01104-12

Schuessler A, Funk A, Lazear HM, Cooper DA, Torres S, Daffis S, Jha BK, Kumagai Y, Takeuchi O, Hertzog P, et al. 2012. West Nile virus noncoding subgenomic RNA contributes to viral evasion of the type I interferon-mediated antiviral response. J Virol 86: 5708-5718. doi:10.1128/JVI.00207-12

Shan C, Xie X, Muruato AE, Rossi SL, Roundy CM, Azar SR, Yang Y, Tesh RB, Bourne N, Barrett AD, et al. 2016. An infectious CDNA clone of Zika virus to study viral virulence, mosquito transmission, and antiviral inhibitors. Cell Host Microbe 19: 891-900. doi:10 .1016/j.chom.2016.05.004

Shan C, Muruato AE, Jagger BW, Richner J, Nunes BTD, Medeiros DBA, Xie X, Nunes JGC, Morabito KM, Kong W-P, et al. 2017a. A single-dose live-attenuated vaccine prevents Zika virus pregnancy transmission and testis damage. Nat Commun 8: 676. doi:10.1038/s41467-017-00737-8

Shan C, Muruato AE, Nunes BTD, Luo $H$, Xie X, Medeiros DBA, Wakamiya M, Tesh RB, Barrett AD, Wang T, et al. 2017b. A live-attenuated Zika virus vaccine candidate induces sterilizing immunity in mouse models. Nat Med 23: 763-767. doi:10.1038/nm.4322

Shen R, Miller WA. 2004. Subgenomic RNA as a riboregulator: negative regulation of RNA replication by Barley yellow dwarf virus subgenomic RNA 2. Virology 327: 196-205. doi:10.1016/j.virol.2004 .06 .025

Shen R, Rakotondrafara AM, Miller WA. 2006. Trans regulation of capindependent translation by a viral subgenomic RNA. J Virol 80: 10045-10054. doi:10.1128/JVI.00991-06

Silva PAGC, Pereira CF, Dalebout TJ, Spaan WJM, Bredenbeek PJ. 2010. An RNA pseudoknot is required for production of yellow fever virus subgenomic RNA by the host nuclease XRN1. J Virol 84: 11395-11406. doi:10.1128/JVI.01047-10

Sit TL, Vaewhongs AA, Lommel SA. 1998. RNA-mediated trans-activation of transcription from a viral RNA. Science 281: 829-832. doi:10.1126/science.281.5378.829

Soto-Acosta R, Xie X, Shan C, Baker CK, Shi P-Y, Rossi SL, GarciaBlanco MA, Bradrick S. 2018. Fragile $X$ mental retardation protein is a Zika virus restriction factor that is antagonized by subgenomic flaviviral RNA. Elife 7: e39023. doi:10.7554/eLife.39023

Steckelberg A-L, Akiyama BM, Costantino DA, Sit TL, Nix JC, Kieft JS. 2018. A folded viral noncoding RNA blocks host cell exoribonucleases through a conformationally dynamic RNA structure. Proc Natl Acad Sci 115: 6404-6409. doi:10.1073/pnas.1802429115 
Strauss JH, Strauss EG. 1994. The alphaviruses: gene expression, replication, and evolution. Microbiol Rev 58: 491-562. doi:10.1128/ MMBR.58.3.491-562.1994

Sztuba-Solińska J, Stollar V, Bujarski JJ. 2011. Subgenomic messenger RNAs: mastering regulation of (+)-strand RNA virus life cycle. Virology 412: 245-255. doi:10.1016/j.virol.2011 .02 .007

Veedu RN, Vester B, Wengel J. 2008. Polymerase chain reaction and transcription using locked nucleic acid nucleotide triphosphates. $J$ Am Chem Soc 130: 8124-8125. doi:10.1021/ja801389n
Wang X, Hou J, Quedenau C, Chen W. 2016. Pervasive isoform-specific translational regulation via alternative transcription start sites in mammals. Mol Syst Biol 12: 875. doi:10.15252/msb.20166941

Xiong Z, Lommel SA. 1991. Red clover necrotic mosaic virus infectious transcripts synthesized in vitro. Virology 182: 388-392. doi:10 .1016/0042-6822(91)90687-7

Xu T, Lei L, Shi J, Wang X, Chen J, Xue M, Sun S, Zhan B, Xia Z, Jiang $N$, et al. 2019. Characterization of maize translational responses to sugarcane mosaic virus infection. Virus Res 259: 97107. doi:10.1016/j.virusres.2018.10.013 

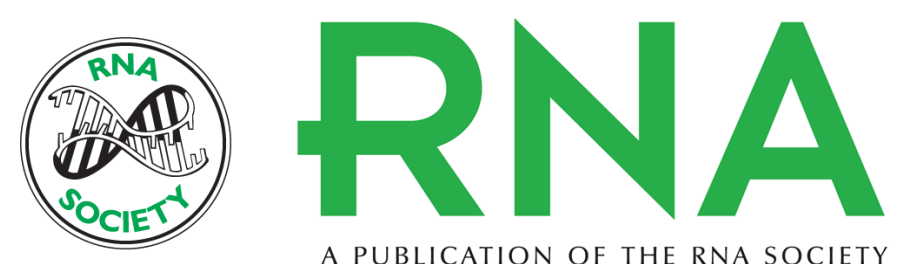

A PUBLICATION OF THE RNA SOCIETY

\section{A rapid and simple quantitative method for specific detection of smaller coterminal RNA by PCR (DeSCo-PCR): application to the detection of viral subgenomic RNAs}

Pulkit Kanodia, K. Reddisiva Prasanth, Vicky C. Roa-Linares, et al.

RNA 2020 26: 888-901 originally published online April 1, 2020

Access the most recent version at doi:10.1261/rna.074963.120

Supplemental Material

References

Open Access

Creative Commons

License

Email Alerting Service
http://rnajournal.cshlp.org/content/suppl/2020/04/01/rna.074963.120.DC1

This article cites 52 articles, 18 of which can be accessed free at: http://rnajournal.cshlp.org/content/26/7/888.full.html\#ref-list-1

Freely available online through the RNA Open Access option.

This article, published in RNA, is available under a Creative Commons License (Attribution 4.0 International), as described at http://creativecommons.org/licenses/by/4.0/.

Receive free email alerts when new articles cite this article - sign up in the box at the top right corner of the article or click here.

\section{|||||||| Providing Precise Solutions for} your research.

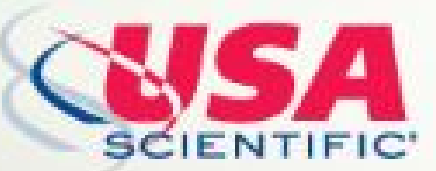

To subscribe to RNA go to:

http://rnajournal.cshlp.org/subscriptions

(C) 2020 Kanodia et al.; Published by Cold Spring Harbor Laboratory Press for the RNA Society 